\title{
Outcome methods used in clinical studies of Chiari malformation Type I: a systematic review
}

\author{
Jacob K. Greenberg, BA, ${ }^{1}$ Eric Milner, BS, ${ }^{1}$ Chester K. Yarbrough, MD, ${ }^{1}$ Kim Lipsey, MLS, ${ }^{3}$ \\ Jay F. Piccirillo, MD, ${ }^{2}$ Matthew D. Smyth, MD, ${ }^{1,4}$ Tae Sung Park, MD, ${ }^{1,4}$ \\ and David D. Limbrick Jr., MD, PhD ${ }^{1,4}$
}

Departments of ${ }^{1}$ Neurological Surgery and ${ }^{2}$ Otolaryngology, and ${ }^{3}$ Bernard Becker Medical Library, Washington University; and ${ }^{4}$ St. Louis Children's Hospital, St. Louis, Missouri

\begin{abstract}
OBJECT Chiari malformation Type I (CM-I) is a common and often debilitating neurological disease. Efforts to improve treatment of $\mathrm{CM}-\mathrm{I}$ are impeded by inconsistent and limited methods of evaluating clinical outcomes. To understand current approaches and lay a foundation for future research, the authors conducted a systematic review of the methods used in original published research articles to evaluate clinical outcomes in patients treated for CM-I.
\end{abstract}

METHODS The authors searched PubMed, Embase, the Cumulative Index to Nursing and Allied Health Literature, ClinicalTrials.gov, and Cochrane databases to identify publications between January 2003 and August 2013 that met the following criteria: 1) reported clinical outcomes in patients treated for CM-l; 2) were original research articles; 3 ) included at least 10 patients or, if a comparative study, at least 5 patients per group; and 4) were restricted to patients with CM-I.

RESULTS Among the 74 papers meeting inclusion criteria, there was wide variation in the outcome methods used. However, all approaches were broadly grouped into 3 categories: 1) "gestalt" impression of overall symptomatic improvement ( $n=45$ papers); 2) postoperative change in specific signs or symptoms $(n=20)$; or 3$)$ results of various standardized assessment scales $(n=22)$. Among standardized scales, 11 general function measures were used, compared with 6 disease-specific tools. Only 3 papers used scales validated in patients with $\mathrm{CM}$-I. To facilitate a uniform comparison of these heterogeneous approaches, the authors appraised articles in multiple domains defined a priori as integral to reporting clinical outcomes in CM-I. Notably, only 7 articles incorporated patient-response instruments when reporting outcome, and only 22 articles explicitly assessed quality of life.

CONCLUSIONS The methods used to evaluate clinical outcomes in CM-I are inconsistent and frequently not comparable, complicating efforts to analyze results across studies. Development, validation, and incorporation of a small number of disease-specific patient-based instruments will improve the quality of research and care of CM-I patients.

http://thejns.org/doi/abs/10.3171/2014.9.JNS14406

KEY WORDS assessment tools; Chiari malformation Type I; outcome methods; systematic review; treatment outcome

$\mathrm{C}$ HIARI malformation Type 1 (CM-I) is a common and often debilitating neurological condition. According to some estimates, CM-I is identified in almost $1 \%$ of all brain and cervical spine MRI studies, ${ }^{55}$ although recent evidence suggests that in children the MRI prevalence may be closer to $4 \%{ }^{80}$ While some individuals with radiological evidence of CM-I are asymptomatic, the clinical manifestations of the disease are broad, complicat- ing efforts to guide patient management and study treatment response.

Corresponding to the recent expansion in the utilization of MRI is the growth in research related to CM-I. The number of PubMed results for the term "Chiari Malformation" increased from 83 in the year 2000 to 162 in the year 2012. This expanding research drive is focused in large part on comparative effectiveness research, ${ }^{18,28}$ and

ABBREVIATIONS CCOS = Chicago Chiari Outcome Scale; CM-I = Chiari malformation Type I; JOA = Japanese Orthopaedic Association; VAS = visual analog scale SUBMITTED February 21, 2014. ACCEPTED September 25, 2014.

INCLUDE WHEN CITING Published online November 7, 2014; DOI: 10.3171/2014.9.JNS14406.

DISCLOSURE This work was supported by a training grant awarded to Jacob Greenberg from the Clinical and Translational Science Award (CTSA) program of the National Center for Advancing Translational Sciences (NCATS) of the NIH (award nos. UL1 TR000448 and TL1 TR000449). This work was also supported in part through personnel support from the Park-Reeves Syringomyelia Research Consortium and a research grant from the American Syringomyelia \& Chiari Alliance Project (ASAP) to Dr. Limbrick and Mr. Greenberg. None of the funding agencies had a direct role in the study design and conduct; data collection, management, analysis, or interpretation; preparing, reviewing, or approving the manuscript prior to submission; or in the decision to submit the manuscript for publication. 
more recently extends to efforts to improve the reporting of clinical outcomes. ${ }^{2,27}$ Nevertheless, despite this recent emphasis on the inclusion of outcome tools in published research, there remains only anecdotal evidence describing the approaches used in contemporary research to evaluate treatment results. Therefore, a critical evaluation of current outcome reporting systems is needed to effectively interpret the published literature and to promote the development of clinically meaningful and rigorously validated outcome measures. The objective of this systematic review is to comprehensively assess the outcome methods used in the contemporary CM-I literature to lay a foundation for future clinical research in this growing field.

\section{Methods}

\section{Inclusion and Exclusion Criteria}

For this review, we only included studies that 1) reported clinical outcomes in patients with CM-I after a therapeutic intervention; 2) were original research articles; 3) included at least 10 patients or, if a comparative study, at least 5 patients per group; and 4) were restricted to patients with CM-I. We excluded from the final analysis review articles, meta-analyses, editorials, abstracts not accompanied by a full-text article, and studies only examining treatment results related to a single sign or symptom, rather than general clinical outcomes.

\section{Search Procedures and Data Abstraction}

We systematically searched the biomedical literature in PubMed, Embase, the Cochrane Database of Systematics Reviews, the Cumulative Index to Nursing and Allied Health Literature, and ClinicalTrials.gov, in addition to performing a manual search of reference lists to identify relevant publications between January 2003 and August 2013. We searched the controlled vocabulary of each database and used plain language in creating a search strategy for the terms "Arnold Chiari Malformation" (including 27 additional variations for Chiari Type I malformation), "Treatment Outcome," "Data Collection," "Questionnaires," and "Outcome and Process Assessment (Health Care)." The final search results were limited to human studies and English-language articles.

All titles and abstracts identified from the search procedure were independently evaluated by 2 reviewers (J.K.G. and E.M.). Instances of disagreement were resolved by discussion, and articles were subsequently chosen for detailed review. Decisions regarding the application of inclusion criteria were agreed upon by both reviewers and D.D.L. Data from full-length articles meeting inclusion criteria, including patient demographics and narrative summaries of outcome methods, were abstracted using a standardized form designed a priori. Outcome systems were then independently evaluated and classified by both reviewers according to predetermined criteria. Disagreements were resolved by discussion, or when needed, a third arbiter (D.D.L.). Descriptive summary statistics were calculated using SPSS (version 21, IBM).

\section{Article Appraisal}

The primary aim for this review was to identify the outcome methods used in the CM-I literature. However, to facilitate a uniform comparison among heterogeneous approaches, we also appraised articles for their adherence to a set of criteria that we defined a priori as key to reporting clinical outcomes in this population. We thus noted 1) inclusion of patient-response instruments (i.e., an outcome measure based on direct patient responses rather than clinician impression of available data); 2) inclusion of any quality of life or overall function assessment; 3) evaluation of new disease-related symptoms that developed after treatment; 4) appropriate multidimensional assessment of outcome for distinct signs or symptoms present preoperatively in individual patients; 5) documentation of rates of revision surgery for persistent disease; and 6) inclusion of detailed reports of headache symptom resolution, given that headaches are the most stereotypical but often poorly defined symptom associated with CM-I.

\section{Results}

Our initial literature search returned a total of 669 results, including 518 unique citations (Fig. 1). After abstract appraisal, 97 articles were selected for full-text review, and 4 additional results were added from review of article references. Our final analysis included 74 articles. Basic study characteristics, including sample size and patient ages, along with additional abstracted information regarding the outcome measures used, are shown in the Appendix.

\section{Outcome Measures}

There was a wide array of methods used to evaluate clinical outcome. However, we identified 3 broad approaches into which all systems could be categorized: 1) providing overall "gestalt" impression of improvement (e.g., patient "improved," "remained unchanged," or "worsened"); 2) providing a description of improvement for each individual or group of signs and symptoms (sign/ symptom-specific reporting); and 3) utilizing one of several standardized outcome scoring systems, defined as any formalized, quantifiable metric for assessing outcome. We further divided standardized scores into those that primarily evaluated disease-specific improvement in signs, symptoms, and overall function-including measures adopted from the general spine literature ${ }^{96}$ and visual analog scales (VASs) for symptoms such as pain ${ }^{1,64}$-and those assessing general quality of life or disability (general function score). Applying this categorization, we found at least 18 different approaches to classifying clinical outcome, although this number is higher if minor modifications made by some groups to gestalt and sign/symptomspecific systems are considered.

Overall, we found that gestalt was the most common system used (used in 45 studies), and 35 articles (47\%) relied on gestalt impression alone to evaluate clinical outcome (Fig. 2). Sign/symptom-specific reporting was present in 20 studies (27\%), and was the lone outcome measure in $9(12 \%)$. Twenty-two articles (30\%) used standardized scoring systems.

Six articles used a total of 11 quality of life or general disability tools to evaluate clinical outcome (Table 1). No measure was used more than once. Four of these 11 tools 


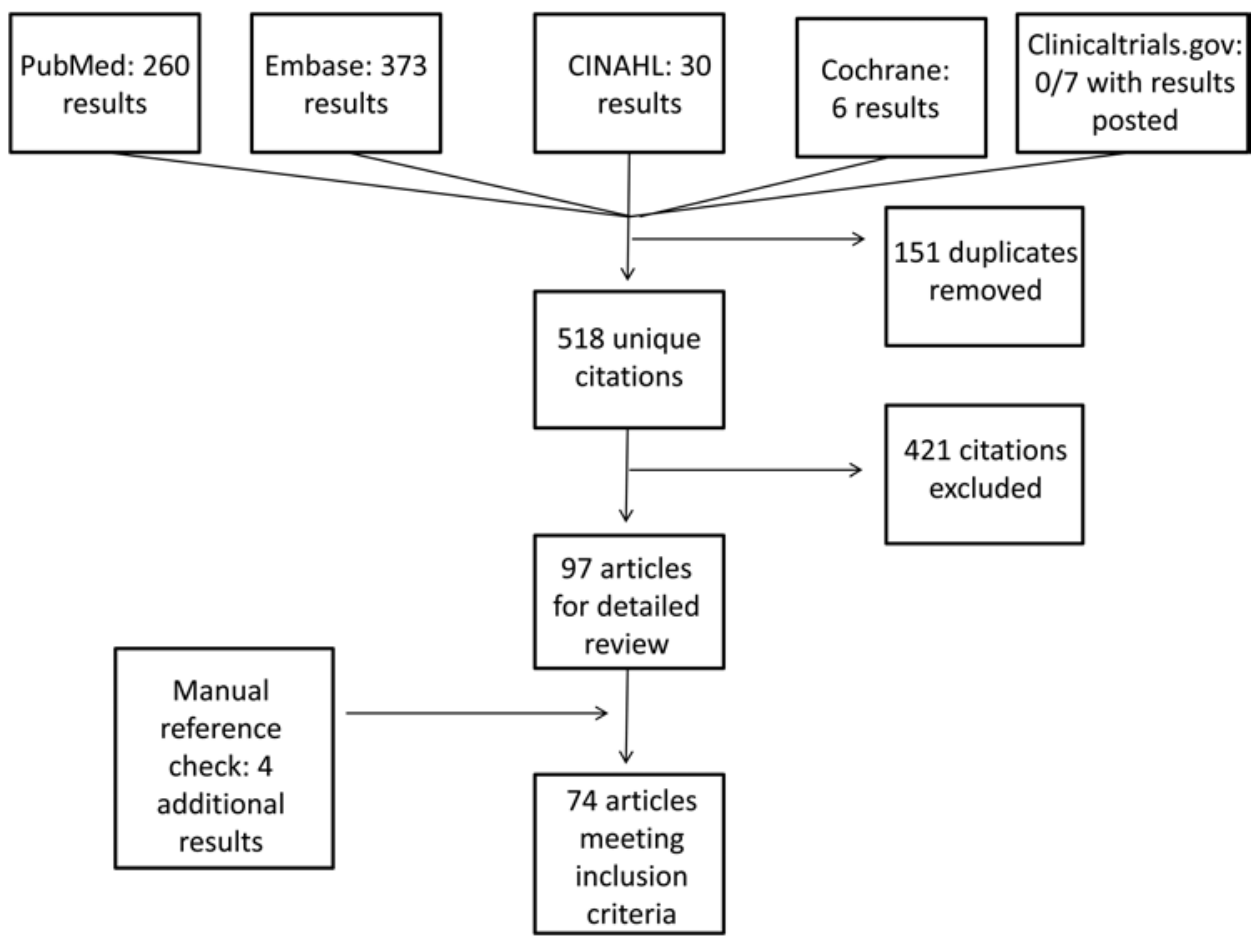

FIG. 1. A flow chart demonstrating the databases searched in the systematic review and the results retrieved. CINAHL $=$ Cumulative Index to Nursing and Allied Health Literature.

demonstrated varying degrees of criterion validity in patients with CM-I, i.e., the instrument's assessments were correlated with well-accepted measures of outcome..$^{13,32}$ One tool, the Headache Disability Index, failed to meet a threshold for accurate discrimination of meaningful improvement prespecified by the study's authors. ${ }^{27}$ Notably, the validity of all 4 tools was established in the same study, and only adult patients were included. ${ }^{27}$ The reliability of these tools was not specifically assessed in patients with CM-I.

Disease-specific scoring systems were more common than general function scores, with a total of 6 scales used in 17 studies (Table 2). The most common measures used were modifications of the Klekamp and Samii score $(n=6$ articles) and the Japanese Orthopaedic Association (JOA) score $(n=4)$. Visual analog scale scores for pain symptoms $(n=3)$ were grouped into a single category. Validations were attempted for 2 of the 6 scales, with 1 (the Chicago Chiari Outcome Scale [CCOS]) demonstrating criterion validity in retrospective chart review, ${ }^{2,93}$ and another (the VAS for either head or neck pain) failing to meet a prespecified threshold for meaningful discrimination of

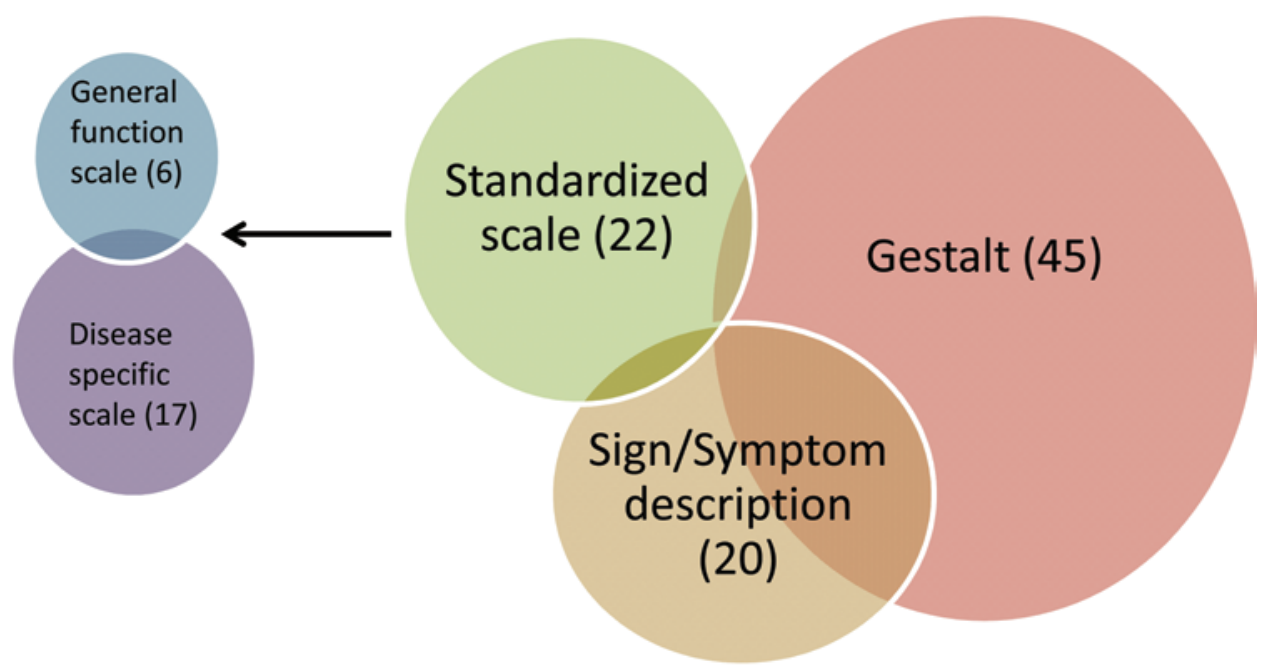

FIG. 2. A summary of the systems used to evaluate clinical outcomes in patients treated for CM-I. The Venn diagram demonstrates the approximate prevalence of each method as well as the overlap of various systems used in the same article. Figure is available in color online only. 
TABLE 1. General quality of life or disability scales used to evaluate clinical outcomes in patients with CM-I

\begin{tabular}{|c|c|c|c|}
\hline Outcome Tool* $^{*}$ & Age Group & CM-I Validity & Reliability in CM-I \\
\hline EuroQol-5D21 & Adults & Yes† & No \\
\hline Headache Disability Index $x^{70}$ & Adults & No & No \\
\hline Karnofsky Performance Scale ${ }^{94}$ & Adults \& children & No & No \\
\hline Neck Disability Index ${ }^{89}$ & Adults & Yes† & No \\
\hline Noudel et al.'s adapted functional grading system ${ }^{63}$ & Adults \& children & Noł & Noł \\
\hline Rankin Scale ${ }^{87} \S$ & Adults \& children & No & No \\
\hline Short Form-12 Health Survey ${ }^{71}$ & Adults & Yest & No \\
\hline Short Form-36 Health Survey ${ }^{71}$ & Adults, unclear if children as well & No & No \\
\hline Sickness Impact Profile ${ }^{59}$ & Adults \& children & No & No \\
\hline VAS for Disease Impact on Daily Life ${ }^{82}$ & Adults \& children & No & No \\
\hline Zung Self-Rating Depression Scale ${ }^{100}$ & Adults & Yes† & No \\
\hline
\end{tabular}

* All outcome tools used only once.

† Demonstrated criterion validity, i.e., the instrument's assessments were correlated with well-accepted measures of outcome.

¥ Scale originally published in French and could not be directly evaluated.

$\S$ The citation provided refers to the modified Rankin Scale, although the article included in the review does not distinguish whether the original or modified Rankin Scale was used.

outcome. ${ }^{27}$ Among the 6 disease-specific tools, reliability statistics in patients with CM-I were only available for the CCOS.

\section{Inclusion of Disease-Appropriate Information}

Our ability to consistently assess the outcome methods used by each study was complicated by the heterogeneity of the approaches identified, including a majority of nonstandardized systems, and the absence of accepted guidelines for reporting treatment results in CM-I. To facilitate uniform evaluation of all studies, we appraised each article for the adequacy of its reporting in 6 domains particularly relevant to patients treated for CM-I. These results are summarized in Table 3.

Overall, only 7 articles (9\%) used direct patient-response instruments when reporting clinical outcome. The vast majority of studies relied on clinician impressions of disease, commonly based on review of the existing medical record. Although the method of data collection was often unspecified, VASs were always considered patientresponse instruments. Specifically among studies using standardized scoring systems, $4(67 \%)$ of 6 articles using general function scores incorporated patient-response instruments, whereas only 3 (18\%) of 17 articles using disease-specific systems included such measures.

When evaluating the inclusion of quality of life assessments, we used a liberal definition that included any explicit consideration during outcome assessment of the influence of disease on quality of life or general function, whether based on clinician or patient impressions and whether a validated system was implemented. Even with this generous definition, less than $30 \%$ of articles included measures that considered the impact of disease on a patient's overall function or well-being.

A minority of articles (38\%) explicitly considered new Chiari-related symptoms developing after surgery when evaluating outcome, more commonly focusing only on resolution of preoperative symptoms. Slightly more common, approximately half $(51 \%)$ of the included studies explicitly provided a multidimensional appraisal of outcome for multiple distinct signs and symptoms present in individual patients preoperatively; the remaining articles typically provided only a 1-dimensional evaluation of whether patients globally "improved" or not. Most articles directly

TABLE 2. Disease-specific scales used to evaluate clinical outcomes in patients treated for $\mathrm{CM}-\mathrm{I}$

\begin{tabular}{|c|c|c|c|c|}
\hline Outcome Tool & Age Group Studied & CM-I Validity & Reliability in CM-I & No. of Studies Used \\
\hline Asgari score (modified) ${ }^{24,39 *}$ & Adults & No & No & 2 \\
\hline $\operatorname{coOs}^{2}$ & Adults \& children & $\begin{array}{l}\text { Yes (criterion } \\
\text { validity) }\end{array}$ & $\begin{array}{l}\text { Mean score deviation }=1.56 \pm 0.74 \\
\text { points (interrater reliability) }\end{array}$ & 2 \\
\hline JOA score ${ }^{96}$ & Adults \& children & No & No & 4 \\
\hline Klekamp \& Samii score $5^{5,37} \dagger$ & Adults \& children & No & No & 6 \\
\hline Limonadi score ${ }^{45}$ & Adults \& children & No & No & 1 \\
\hline VAS-pain ${ }^{64} \ddagger$ & Adults & No & No & 3 \\
\hline
\end{tabular}


TABLE 3. Assessment of 6 key domains relevant to reporting clinical outcome in $\mathrm{CM}-\mathrm{I}$ and the number of papers fulfilling each domain

\begin{tabular}{|c|c|}
\hline Study Domain & $\begin{array}{c}\text { No. of Papers } \\
(\%)\end{array}$ \\
\hline \multicolumn{2}{|l|}{ Source of outcome evaluation } \\
\hline Clinician impression & $67(90.5)$ \\
\hline Patient-response instrument & $5(6.8)$ \\
\hline Clinician impression + patient-response instrument & $2(2.7)$ \\
\hline Quality of life assessed & $22(29.7)$ \\
\hline New symptoms reported & $28(37.8)$ \\
\hline Multidimensional assessment performed & $38(51.4)$ \\
\hline Revision surgery reported & $45(60.8)$ \\
\hline \multicolumn{2}{|l|}{ Method of reporting headache symptoms } \\
\hline Not reported or included in general pain scale & $19(25.7)$ \\
\hline Described a single "headache" group & $14(18.9)$ \\
\hline Combined headache w/ neck or back pain & $6(8.1)$ \\
\hline Evaluated headaches by specific location/character & $14(18.9)$ \\
\hline Unclear & $21(28.4)$ \\
\hline
\end{tabular}

reported rates of revision surgery for persistent disease, although a sizable minority (39\%) did not.

In assessing how each article evaluated patients' common but often difficult-to-characterize headache symptoms, we identified 4 general approaches that were used. Fourteen studies (19\%) reported headache outcome based on specific location or character. More commonly, headaches were not reported or were grouped in a general pain category (26\%). In addition, $19 \%$ of articles reported all headaches as a single symptom type, and $28 \%$ of articles did not provide sufficient information to allow confident determination of how outcomes were analyzed.

\section{Discussion}

To our knowledge, this is the first systematic and comprehensive assessment of the outcome methods used in the CM-I literature. Overall, we found a great deal of inconsistency among the approaches used, with at least 18 different combinations of outcome systems identified. Most studies used gestalt impression to define outcome, with less than one-third using a standard scoring system and far fewer relying on a tool specifically validated in patients with CM-I. These results highlight the significant need for commonly accepted standards to guide clinical outcome reporting in CM-I research.

Identifying one, or even a few, consistent approaches to reporting outcome is essential to interpreting results from individual investigations as well as to comparing results across studies. Simple gestalt impression, the most common method identified, provides little detail about disease evolution and, due to its inherent ambiguity, is likely to be applied inconsistently across and even within studies. ${ }^{22}$ Likewise, when not part of a composite score, sign/ symptom-specific reporting does not permit a clear comparison of results across patients. These shortcomings and the diversity of systems currently used severely limit the ability to generalize results beyond a single sample. An initiative by the National Institute of Neurological Disorders and Stroke, the Common Data Elements Project, ${ }^{61}$ has addressed the inconsistent reporting of results for a number of neurological conditions, ${ }^{47,48,75}$ but only now are foundations and other groups with an interest in CM-I considering such efforts.

While reliable and consistent reporting is critical, another key consideration in outcomes assessment is instrument validity. Among the 17 standardized systems identified, 5 have been validated in CM-I patients. ${ }^{2,27,93}$ However, only 1 , the CCOS, has been validated in adults and children. ${ }^{2,93} \mathrm{~A} 4$-item scale assessing pain symptoms, nonpain symptoms, functionality, and complications, the CCOS is designed for retrospective chart review and thus is not suited for prospectively measuring patient-defined disease burden before and after treatment. In addition, some CCOS subscores, particularly functionality, have poor interrater reliability. ${ }^{93}$ Notably, all instrument validations focused on criterion validity, or the extent to which the system at hand correlates with well-accepted measures. ${ }^{13,32}$ By contrast, the recently developed Chiari Symptom Profile has shown strong content validity (i.e., covering all the areas intended) but has not yet been applied to outcomes research. ${ }^{60}$ Demonstrating validity in multiple domains is an important aspect of developing a meaningful outcome scale.

Because symptomatic outcomes for patients with CM-I are inherently subjective, one critical but often overlooked component of measuring outcomes is the utilization of patient-response instruments. In recent years, major initiatives including the Patient-Centered Outcome Research Institute ${ }^{25,76,90}$ and the Patient-Reported Outcomes Measurement Information System (http://www.nihpromis. org/) have promoted the incorporation of patient perspectives and values into treatment decisions. However, despite such efforts, only 7 articles (9\%) in the contemporary CM-I literature incorporated any direct measure of patient opinion when reporting outcome. Consequently, there is little evidence regarding how patients' views of their own health change after CM-I surgery. Future research should strive to incorporate direct patient responses when assessing clinical outcome.

While patient-response measures lay a foundation for meaningful assessments, we identified several additional characteristics necessary in studies evaluating outcome in patients with CM-I. Many of the shortcomings we observed, such as not accounting for new symptoms postoperatively or not providing a multidimensional outcome assessment of distinct signs and symptoms present preoperatively, likely reflect the reliance on 1-dimensional gestalt assessments. Similarly, the limited assessment of headache symptoms reflects the need for validated tools that capture the complexity of the symptoms present in patients with CM-I.

To aid the development of novel outcome metrics, we created the checklist shown in Table 4. This Chiari-focused framework can be used along with general guides for evaluating health measurement instruments ${ }^{56}$ to appraise the quality of future scales. Until new metrics are developed, researchers interested in studying general 
TABLE 4. A checklist for evaluating clinical outcome methods in CM-I treatment studies

\begin{tabular}{|c|c|c|}
\hline Key elements of a CM-I clinical outcome metric & Yes & No \\
\hline Do measures of symptomatic outcome incorporate direct patient reporting? & $(\quad)$ & () \\
\hline Does the outcome metric include a specific assessment of patient quality of life? & () & () \\
\hline Does the outcome metric assess for new symptoms that developed after initial surgery? & () & ( \\
\hline $\begin{array}{l}\text { Does the outcome metric provide a sufficient multidimensional assessment of outcome for distinct signs } \\
\text { \& symptoms present preoperatively in individual patients? }\end{array}$ & () & ( \\
\hline Does the outcome metric assess in sufficient detail the location \& character of headache symptoms? & () & () \\
\hline Does the study report the rate of revision surgery for persistent disease? & () & () \\
\hline Is the outcome metric valid in CM-I patients?* & $(\quad)$ & ( \\
\hline Is the outcome metric reliable in CM-I patients? & $(\quad)$ & () \\
\hline
\end{tabular}

quality of life could use tools such as the EuroQol-5D, which has shown criterion validity in adults. ${ }^{27}$ However, given the substantial limitations of current systems, we are unable to endorse 1 or more disease-specific tools. Rather, we recommend researchers use our proposed checklist to weigh the strengths and weaknesses of existing methods in the context of their studies' goals.

Significantly, this study has several limitations. Most importantly, the classifications outlined, such as whether an article considered new symptoms developing after treatment or how an article evaluated multiple unique signs and symptoms in individual patients, inevitably involved subjective determination based on the limited information provided in each article. In addition, this review was restricted to the English-language literature, which may have excluded certain metrics.

\section{Conclusions}

In this review, we have identified significant weaknesses in the contemporary methods used to assess clinical outcomes in patients with CM-I and have provided a framework to improve future evaluations. The conclusive trends identified in this review, including the reliance on gestalt measures, highlight the critical need for multidisciplinary collaboration to develop patient-based, validated, and disease-specific tools for reporting clinical outcome in CM-I. Adopting such standardized scales will enable the most informative and generalizable conclusions to be drawn from each study and will serve as a critical step toward improving patient care.

\section{References}

1. Alfieri A, Pinna G: Long-term results after posterior fossa decompression in syringomyelia with adult Chiari Type I malformation. Clinical article. J Neurosurg Spine 17:381387, 2012

2. Aliaga L, Hekman KE, Yassari R, Straus D, Luther G, Chen $\mathrm{J}$, et al: A novel scoring system for assessing Chiari malformation type I treatment outcomes. Neurosurgery 70:656665,2012

3. Anderson RC, Dowling KC, Feldstein NA, Emerson RG: Chiari I malformation: potential role for intraoperative electrophysiologic monitoring. J Clin Neurophysiol 20:65-72, 2003

4. Arora P, Behari S, Banerji D, Chhabra DK, Jain VK: Factors influencing the outcome in symptomatic Chiari I malformation. Neurol India 52:470-474, 2004

5. Arora P, Pradhan PK, Behari S, Banerji D, Das BK, Chhabra DK, et al: Chiari I malformation related syringomyelia: radionuclide cisternography as a predictor of outcome. Acta Neurochir (Wien) 146:119-130, 2004

6. Arruda JA, Costa CM, Tella OI Jr: Results of the treatment of syringomyelia associated with Chiari malformation: analysis of 60 cases. Arq Neuropsiquiatr 62 (2A):237-244, 2004

7. Attenello FJ, McGirt MJ, Garcés-Ambrossi GL, Chaichana KL, Carson B, Jallo GI: Suboccipital decompression for Chiari I malformation: outcome comparison of duraplasty with expanded polytetrafluoroethylene dural substitute versus pericranial autograft. Childs Nerv Syst 25:183-190, 2009

8. Attenello FJ, McGirt MJ, Gathinji M, Datoo G, Atiba A, Weingart J, et al: Outcome of Chiari-associated syringomyelia after hindbrain decompression in children: analysis of 49 consecutive cases. Neurosurgery 62:1307-1313, 2008

9. Bao C, Yang F, Liu L, Wang B, Li D, Gu Y, et al: Surgical treatment of Chiari I malformation complicated with syringomyelia. Exp Ther Med 5:333-337, 2013

10. Batzdorf U, McArthur DL, Bentson JR: Surgical treatment of Chiari malformation with and without syringomyelia: experience with 177 adult patients. Clinical article. J Neurosurg 118:232-242, 2013

11. Behari S, Kalra SK, Kiran Kumar MV, Salunke P, Jaiswal AK, Jain VK: Chiari I malformation associated with atlantoaxial dislocation: focussing on the anterior cervico-medullary compression. Acta Neurochir (Wien) 149:41-50, 2007

12. Caldarelli M, Novegno F, Vassimi L, Romani R, Tamburrini G, Di Rocco C: The role of limited posterior fossa craniectomy in the surgical treatment of Chiari malformation Type I: experience with a pediatric series. J Neurosurg 106 (3 Suppl):187-195, 2007

13. Carmines EG, Zeller RA: Reliability and Validity Assessment. Quantitative Applications in the Social Sciences. Newbury Park, CA: Sage Publications, Vol 17, 1979

14. Chauvet D, Carpentier A, George B: Dura splitting decompression in Chiari type 1 malformation: clinical experience and radiological findings. Neurosurg Rev 32:465-470, 2009

15. Cui LG, Jiang L, Zhang HB, Liu B, Wang JR, Jia JW, et al: Monitoring of cerebrospinal fluid flow by intraoperative ultrasound in patients with Chiari I malformation. Clin Neurol Neurosurg 113:173-176, 2011

16. Di X: Endoscopic suboccipital decompression on pediatric Chiari type I. Minim Invasive Neurosurg 52:119-125, 2009

17. Dones J, De Jesús O, Colen CB, Toledo MM, Delgado M: Clinical outcomes in patients with Chiari I malformation: a review of 27 cases. Surg Neurol 60:142-148, 2003

18. Durham SR, Fjeld-Olenec K: Comparison of posterior fossa 
decompression with and without duraplasty for the surgical treatment of Chiari malformation Type I in pediatric patients: a meta-analysis. J Neurosurg Pediatr 2:42-49, 2008

19. El-Ghandour NMF: Long-term outcome of surgical management of adult Chiari I malformation. Neurosurg Rev 35:537-547, 2012

20. Erdogan E, Cansever T, Secer HI, Temiz C, Sirin S, Kabatas $\mathrm{S}$, et al: The evaluation of surgical treatment options in the Chiari Malformation Type I. Turk Neurosurg 20:303-313, 2010

21. EuroQol-Group: About EQ-5D. (http://www.euroqol.org/ about-eq-5d.html) [Accessed October 1, 2014]

22. Feinstein AR: Clinical Epidemiology: The Architecture of Clinical Research. Philadelphia: WB Saunders, 1985

23. Foreman P, Safavi-Abbasi S, Talley MC, Boeckman L, Mapstone TB: Perioperative outcomes and complications associated with allogeneic duraplasty for the management of Chiari malformations Type I in 48 pediatric patients. Clinical article. J Neurosurg Pediatr 10:142-149, 2012

24. Furtado SV, Thakar S, Hegde AS: Correlation of functional outcome and natural history with clinicoradiological factors in surgically managed pediatric Chiari I malformation. Neurosurgery 68:319-328, 2011

25. Gabriel SE, Normand SL: Getting the methods right-the foundation of patient-centered outcomes research. N Engl J Med 367:787-790, 2012

26. Galarza M, Sood S, Ham S: Relevance of surgical strategies for the management of pediatric Chiari type I malformation. Childs Nerv Syst 23:691-696, 2007

27. Godil SS, Parker SL, Zuckerman SL, Mendenhall SK, McGirt MJ: Accurately measuring outcomes after surgery for adult Chiari I malformation: determining the most valid and responsive instruments. Neurosurgery 72:820-827, 2013

28. Hankinson T, Tubbs RS, Wellons JC: Duraplasty or not? An evidence-based review of the pediatric Chiari I malformation. Childs Nerv Syst 27:35-40, 2011

29. Heiss JD, Suffredini G, Smith R, DeVroom HL, Patronas NJ, Butman JA, et al: Pathophysiology of persistent syringomyelia after decompressive craniocervical surgery. Clinical article. J Neurosurg Spine 13:729-742, 2010

30. Hekman KE, Aliaga L, Straus D, Luther A, Chen J, Sampat A, et al: Positive and negative predictors for good outcome after decompressive surgery for Chiari malformation type 1 as scored on the Chicago Chiari Outcome Scale. Neurol Res 34:694-700, 2012

31. Hoffman CE, Souweidane MM: Cerebrospinal fluid-related complications with autologous duraplasty and arachnoid sparing in type I Chiari malformation. Neurosurgery 62 (3 Suppl 1):156-161, 2008

32. Hulley SB, Cummings SR, Browner WS, Grady DG, Newman TB: Designing Clinical Research, ed 3. Philadelphia: Lippincott Williams \& Wilkins, 2007

33. Hyun SJ, Moon KY, Kwon JW, Lee CH, Kim J, Kim KJ, et al: Chiari I malformation associated with syringomyelia: can foramen magnum decompression lead to restore cervical alignment? Eur Spine J 22:2520-2525, 2013

34. Kalb S, Perez-Orribo L, Mahan M, Theodore N, Nakaji P, Bristol RE: Evaluation of operative procedures for symptomatic outcome after decompression surgery for Chiari type I malformation. J Clin Neurosci 19:1268-1272, 2012

35. Kim LJ, Rekate HL, Klopfenstein JD, Sonntag VKH: Treatment of basilar invagination associated with Chiari I malformations in the pediatric population: cervical reduction and posterior occipitocervical fusion. J Neurosurg 101 (2 Suppl):189-195, 2004

36. Klekamp J: Neurological deterioration after foramen magnum decompression for Chiari malformation type I: old or new pathology? Clinical article. J Neurosurg Pediatr 10:538-547, 2012
37. Klekamp J: Surgical treatment of Chiari I malformationanalysis of intraoperative findings, complications, and outcome for 371 foramen magnum decompressions. Neurosurgery 71:365-380, 2012

38. Klekamp J, Samii M: Introduction of a score system for the clinical evaluation of patients with spinal processes. Acta Neurochir (Wien) 123:221-223, 1993

39. Koç K, Anik Y, Anik I, Cabuk B, Ceylan S: Chiari 1 malformation with syringomyelia: correlation of phase-contrast cine MR imaging and outcome. Turk Neurosurg 17:183-192, 2007

40. Kumar R, Kalra SK, Vaid VK, Mahapatra AK: Chiari I malformation: surgical experience over a decade of management. Br J Neurosurg 22:409-414, 2008

41. Kunert P, Janowski M, Zakrzewska A, Marchel A: Comparision of results between two different techniques of craniocervical decompression in patients with Chiari I malformation. Neurol Neurochir Pol 43:337-345, 2009

42. Lam FC, Penumaka A, Chen CC, Fischer EG, Kasper EM: Fibrin sealant augmentation with autologous pericranium for duraplasty after suboccipital decompression in Chiari 1 patients: a case series. Surg Neurol Int 4:6, 2013

43. Lee HS, Lee SH, Kim ES, Kim JS, Lee JI, Shin HJ, et al: Surgical results of arachnoid-preserving posterior fossa decompression for Chiari I malformation with associated syringomyelia. J Clin Neurosci 19:557-560, 2012

44. Levo H, Tapani E, Karppinen A, Kentala E: Chiari Malformation in otology practice. Auris Nasus Larynx 37:95-99, 2010

45. Limonadi FM, Selden NR: Dura-splitting decompression of the craniocervical junction: reduced operative time, hospital stay, and cost with equivalent early outcome. J Neurosurg 101 (2 Suppl):184-188, 2004

46. Litvack ZN, Lindsay RA, Selden NR: Dura splitting decompression for Chiari I malformation in pediatric patients: clinical outcomes, healthcare costs, and resource utilization. Neurosurgery 72:922-929, 2013

47. Loring DW, Lowenstein DH, Barbaro NM, Fureman BE, Odenkirchen J, Jacobs MP, et al: Common data elements in epilepsy research: development and implementation of the NINDS epilepsy CDE project. Epilepsia 52:1186-1191, 2011

48. Lynch DR, Pandolfo M, Schulz JB, Perlman S, Delatycki MB, Payne RM, et al: Common data elements for clinical research in Friedreich's ataxia. Mov Disord 28:190-195, 2013

49. Massimi L, Caldarelli M, Paternoster G, Novegno F, Tamburrini G, Di Rocco C: Mini-invasive surgery for Chiari type I malformation. Neuroradiol J 21:65-70, 2008

50. Massimi L, Pravatà E, Tamburrini G, Gaudino S, Pettorini B, Novegno F, et al: Endoscopic third ventriculostomy for the management of Chiari I and related hydrocephalus: outcome and pathogenetic implications. Neurosurgery 68:950-956, 2011

51. McGirt MJ, Atiba A, Attenello FJ, Wasserman BA, Datoo G, Gathinji M, et al: Correlation of hindbrain CSF flow and outcome after surgical decompression for Chiari I malformation. Childs Nerv Syst 24:833-840, 2008

52. McGirt MJ, Attenello FJ, Atiba A, Garces-Ambrossi G, Datoo G, Weingart JD, et al: Symptom recurrence after suboccipital decompression for pediatric Chiari I malformation: analysis of 256 consecutive cases. Childs Nerv Syst 24:1333-1339, 2008

53. McGirt MJ, Attenello FJ, Datoo G, Gathinji M, Atiba A, Weingart JD, et al: Intraoperative ultrasonography as a guide to patient selection for duraplasty after suboccipital decompression in children with Chiari malformation Type I. J Neurosurg Pediatr 2:52-57, 2008

54. McGirt MJ, Nimjee SM, Fuchs HE, George TM: Relationship of cine phase-contrast magnetic resonance imaging with outcome after decompression for Chiari I malformations. Neurosurgery 59:140-146, 2006 
55. Meadows J, Kraut M, Guarnieri M, Haroun RI, Carson BS: Asymptomatic Chiari Type I malformations identified on magnetic resonance imaging. J Neurosurg 92:920-926, 2000

56. Mokkink LB, Terwee CB, Patrick DL, Alonso J, Stratford PW, Knol DL, et al: The COSMIN checklist for assessing the methodological quality of studies on measurement properties of health status measurement instruments: an international Delphi study. Qual Life Res 19:539-549, 2010

57. Mokkink LB, Terwee CB, Patrick DL, Alonso J, Stratford PW, Knol DL, et al: The COSMIN study reached international consensus on taxonomy, terminology, and definitions of measurement properties for health-related patient-reported outcomes. J Clin Epidemiol 63:737-745, 2010

58. Mottolese C, Szathmari A, Simon E, Rousselle C, RicciFranchi AC, Hermier M: Treatment of Chiari type I malformation in children: the experience of Lyon. Neurol Sci 32 (Suppl 3):S325-S330, 2011

59. Mueller D, Oro' JJ: Prospective analysis of self-perceived quality of life before and after posterior fossa decompression in 112 patients with Chiari malformation with or without syringomyelia. Neurosurg Focus 18(2):ECP2, 2005

60. Mueller DM, Oro' JJ: The Chiari Symptom Profile: development and validation of a Chiari-/syringomyelia-specific questionnaire. J Neurosci Nurs 45:205-210, 2013

61. National Institute of Neurological Disorders and Stroke: Project overview. NINDS Common Data Elements. (http:// www.commondataelements.ninds.nih.gov/ProjReview. aspx\#tab=Introduction) [Accessed September 27, 2014]

62. Navarro R, Olavarria G, Seshadri R, Gonzales-Portillo G, McLone DG, Tomita T: Surgical results of posterior fossa decompression for patients with Chiari I malformation. Childs Nerv Syst 20:349-356, 2004

63. Noudel R, Gomis P, Sotoares G, Bazin A, Pierot L, Pruvo JP, et al: Posterior fossa volume increase after surgery for Chiari malformation Type I: a quantitative assessment using magnetic resonance imaging and correlations with the treatment response. Clinical article. J Neurosurg 115:647-658, 2011

64. Ono A, Numasawa T, Wada K, Yokoyama T, Takeuchi K, Suetsuna F, et al: Surgical outcomes of foramen magnum decompression for syringomyelia associated with Chiari I malformation: relation between the location of the syrinx and body pain. J Orthop Sci 15:299-304, 2010

65. Ono A, Suetsuna F, Ueyama K, Yokoyama T, Aburakawa S, Numasawa T, et al: Surgical outcomes in adult patients with syringomyelia associated with Chiari malformation type I: the relationship between scoliosis and neurological findings. J Neurosurg Spine 6:216-221, 2007

66. Panigrahi M, Reddy BP, Reddy AK, Reddy JJM: CSF flow study in Chiari I malformation. Childs Nerv Syst 20:336340, 2004

67. Perrini P, Benedetto N, Tenenbaum R, Di Lorenzo N: Extraarachnoidal cranio-cervical decompression for syringomyelia associated with Chiari I malformation in adults: technique assessment. Acta Neurochir (Wien) 149:1015-1023, 2007

68. Prat R, Galeano I: Pain improvement in patients with syringomyelia and Chiari I malformation treated with suboccipital decompression and tonsillar coagulation. J Clin Neurosci 16:531-534, 2009

69. Pritz MB: Surgical treatment of Chiari I malformation: simplified technique and clinical results. Skull Base 13:173-177, 2003

70. Pryse-Phillips W: Evaluating migraine disability: the headache impact test instrument in context. Can J Neurol Sci 29 (Suppl 2):S11-S15, 2002

71. QualityMetric: SF Health Surveys. (http://www.quality metric.com/WhatWeDo/SFHealthSurveys/tabid/184/Default. aspx) [Accessed September 27, 2014]

72. Ramnarayan R, Praharaj MS, Jayakumar PN: Chiari 1 mal- formations: an Indian hospital experience. Singapore Med J 49:1029-1034, 2008

73. Romero FR, Pereira CA: Suboccipital craniectomy with or without duraplasty: what is the best choice in patients with Chiari type 1 malformation? Arq Neuropsiquiatr 68:623626,2010

74. Sakushima K, Hida K, Yabe I, Tsuboi S, Uehara R, Sasaki $\mathrm{H}$ : Different surgical treatment techniques used by neurosurgeons and orthopedists for syringomyelia caused by Chiari I malformation in Japan. Clinical article. J Neurosurg Spine 18:588-592, 2013

75. Saver JL, Warach S, Janis S, Odenkirchen J, Becker K, Benavente $\mathrm{O}$, et al: Standardizing the structure of stroke clinical and epidemiologic research data: the National Institute of Neurological Disorders and Stroke (NINDS) Stroke Common Data Element (CDE) project. Stroke 43:967-973, 2012

76. Selby JV, Beal AC, Frank L: The Patient-Centered Outcomes Research Institute (PCORI) national priorities for research and initial research agenda. JAMA 307:1583-1584, 2012

77. Shamji MF, Ventureyra EC, Baronia B, Nzau M, Vassilyadi M: Classification of symptomatic Chiari I malformation to guide surgical strategy. Can J Neurol Sci 37:482-487, 2010

78. Sivaramakrishnan A, Alperin N, Surapaneni S, Lichtor T: Evaluating the effect of decompression surgery on cerebrospinal fluid flow and intracranial compliance in patients with Chiari malformation with magnetic resonance imaging flow studies. Neurosurgery 55:1344-1351, 2004

79. Spena G, Bernucci C, Garbossa D, Valfrè W, Versari P: Clinical and radiological outcome of craniocervical osteodural decompression for Chiari I-associated syringomyelia. Neurosurg Rev 33:297-304, 2010

80. Strahle J, Muraszko KM, Kapurch J, Bapuraj JR, Garton HJ, Maher CO: Chiari malformation Type I and syrinx in children undergoing magnetic resonance imaging. Clinical article. J Neurosurg Pediatr 8:205-213, 2011

81. Takayasu M, Takagi T, Hara M, Anzai M: A simple technique for expansive suboccipital cranioplasty following foramen magnum decompression for the treatment of syringomyelia associated with Chiari I malformation. Neurosurg Rev 27:173-177, 2004

82. Tisell M, Wallskog J, Linde M: Long-term outcome after surgery for Chiari I malformation. Acta Neurol Scand 120:295-299, 2009

83. Tubbs RS, Beckman J, Naftel RP, Chern JJ, Wellons JC III, Rozzelle CJ, et al: Institutional experience with 500 cases of surgically treated pediatric Chiari malformation Type I. J Neurosurg Pediatr 7:248-256, 2011 Clinical article.

84. Tubbs RS, Iskandar BJ, Bartolucci AA, Oakes WJ: A critical analysis of the Chiari 1.5 malformation. J Neurosurg 101 (2 Suppl):179-183, 2004

85. Tubbs RS, McGirt MJ, Oakes WJ: Surgical experience in 130 pediatric patients with Chiari I malformations. J Neurosurg 99:291-296, 2003

86. Valentini L, Visintini S, Saletti V, Chiapparini L, Estienne M, Solero CL: Treatment for Chiari 1 malformation (CIM): analysis of a pediatric surgical series. Neurol Sci 32 (Suppl 3):S321-S324, 2011

87. van Swieten JC, Koudstaal PJ, Visser MC, Schouten HJ, van Gijn J: Interobserver agreement for the assessment of handicap in stroke patients. Stroke 19:604-607, 1988

88. Ventureyra EC, Aziz HA, Vassilyadi M: The role of cine flow MRI in children with Chiari I malformation. Childs Nerv Syst 19:109-113, 2003

89. Vernon H: The Neck Disability Index: state-of-the-art, 19912008. J Manipulative Physiol Ther 31:491-502, 2008

90. Washington AE, Lipstein SH: The Patient-Centered Outcomes Research Institute-promoting better information, decisions, and health. N Engl J Med 365:e31, 2011

91. Wetjen NM, Heiss JD, Oldfield EH: Time course of syringo- 
myelia resolution following decompression of Chiari malformation Type I. J Neurosurg Pediatr 1:118-123, 2008

92. Williams LE, Vannemreddy PS, Watson KS, Slavin KV: The need in dural graft suturing in Chiari I malformation decompression: a prospective, single-blind, randomized trial comparing sutured and sutureless duraplasty materials. Surg Neurol Int 4:26, 2013

93. Yarbrough CK, Greenberg JK, Smyth MD, Leonard JR, Park TS, Limbrick DD Jr: External validation of the Chicago Chiari Outcome Scale. Clinical article. J Neurosurg Pediatr 13:679-684, 2014

94. Yates JW, Chalmer B, McKegney FP: Evaluation of patients with advanced cancer using the Karnofsky performance status. Cancer 45:2220-2224, 1980

95. Yeh DD, Koch B, Crone KR: Intraoperative ultrasonography used to determine the extent of surgery necessary during posterior fossa decompression in children with Chiari malformation type I. J Neurosurg 105 (1 Suppl):26-32, 2006

96. Yilmaz A, Kanat A, Musluman AM, Colak I, Terzi Y, Kayac1 $\mathrm{S}$, et al: When is duraplasty required in the surgical treatment of Chiari malformation type I based on tonsillar descending grading scale? World Neurosurg 75:307-313, 2011

97. Zamel K, Galloway G, Kosnik EJ, Raslan M, Adeli A: Intraoperative neurophysiologic monitoring in 80 patients with Chiari I malformation: role of duraplasty. J Clin Neurophysiol 26:70-75, 2009

98. Zhang Y, Zhang N, Qiu H, Zhou J, Li P, Ren M, et al: An efficacy analysis of posterior fossa decompression techniques in the treatment of Chiari malformation with associated syringomyelia. J Clin Neurosci 18:1346-1349, 2011
99. Zhang ZQ, Chen YQ, Chen YA, Wu X, Wang YB, Li XG: Chiari I malformation associated with syringomyelia: a retrospective study of 316 surgically treated patients. Spinal Cord 46:358-363, 2008

100. Zung WW, Richards CB, Short MJ: Self-rating depression scale in an outpatient clinic. Further validation of the SDS. Arch Gen Psychiatry 13:508-515, 1965

\section{Author Contributions}

Conception and design: Greenberg, Milner, Lipsey, Piccirillo, Limbrick. Acquisition of data: Greenberg, Milner. Analysis and interpretation of data: Greenberg, Milner, Yarbrough, Piccirillo, Smyth, Park, Limbrick. Drafting the article: Greenberg, Lipsey. Critically revising the article: all authors. Reviewed submitted version of manuscript: all authors. Approved the final version of the manuscript on behalf of all authors: Greenberg. Statistical analysis: Greenberg. Administrative/technical/material support: Limbrick. Study supervision: Limbrick.

\section{Correspondence}

Jacob K. Greenberg, Neurological Surgery, St. Louis Children's Hospital, One Children's Way, 4S20, St. Louis, MO 63110. email: greenbergj@wusm.wustl.edu. 
APPENDIX: Complete list of, and basic information about, each article meeting inclusion criteria

\begin{tabular}{|c|c|c|c|c|c|}
\hline Authors \& Year & $\begin{array}{l}\text { Sample } \\
\text { Size }\end{array}$ & $\begin{array}{l}\text { Participant Age } \\
\text { Group }\end{array}$ & $\begin{array}{l}\text { Outcome } \\
\text { System }\end{array}$ & Standardized Score & $\begin{array}{c}\text { Source of } \\
\text { Outcome Data }\end{array}$ \\
\hline Alfieri \& Pinna, 2012 & 109 & Adult & DSS + SSR & VAS-pain & $\mathrm{Cl}, \mathrm{PRI}$ \\
\hline Aliaga, et al., 2012 & 146 & Child + adult & DSS & $\operatorname{ccos}$ & $\mathrm{Cl}$ \\
\hline Anderson et al., 2003 & 11 & Child + adult & Gestalt & NA & $\mathrm{Cl}$ \\
\hline Arora et al., $2004^{5}$ & 17 & Child + adult & DSS & Klekamp \& Samii score & $\mathrm{Cl}$ \\
\hline Arora et al., $2004^{4}$ & 48 & Child + adult & DSS & Klekamp \& Samii score & $\mathrm{Cl}$ \\
\hline Arruda et al., 2004 & 60 & Child + adult & Gestalt + SSR & NA & $\mathrm{Cl}$ \\
\hline Attenello et al., 2008 & 49 & Child & Gestalt + SSR & NA & $\mathrm{Cl}$ \\
\hline Attenello et al., 2009 & 67 & Child & Gestalt & NA & $\mathrm{Cl}$ \\
\hline Bao et al., 2013 & 147 & Child + adult & Gestalt & NA & $\mathrm{Cl}$ \\
\hline Batzdorf et al., 2013 & 177 & Child + adult & SSR & NA & $\mathrm{Cl}$ \\
\hline Behari et al., 2007 & 39 & Child + adult & DSS & Klekamp \& Samii score & $\mathrm{Cl}$ \\
\hline Caldarelli et al., 2007 & 30 & Child & Gestalt & NA & $\mathrm{Cl}$ \\
\hline Chauvet et al., 2009 & 11 & Adult & SSR & NA & $\mathrm{Cl}$ \\
\hline Cui et al., 2011 & 20 & Unclear & Gestalt & NA & $\mathrm{Cl}$ \\
\hline Di, 2009 & 26 & Child & Gestalt + SSR & NA & $\mathrm{Cl}$ \\
\hline Dones et al., 2003 & 27 & Child + adult & SSR & NA & $\mathrm{Cl}$ \\
\hline El-Ghandour, 2012 & 46 & Adult & Gestalt & NA & $\mathrm{Cl}$ \\
\hline Erdogan et al., 2010 & 27 & Unclear & Gestalt & NA & $\mathrm{Cl}$ \\
\hline Foreman et al., 2012 & 48 & Child & Gestalt & NA & $\mathrm{Cl}$ \\
\hline Furtado et al., 2011 & 20 & Child & DSS + SSR & Asgari score & $\mathrm{Cl}$ \\
\hline Galarza et al., 2007 & 60 & Child & Gestalt & NA & $\mathrm{Cl}$ \\
\hline Godil et al., 2013 & 50 & Adult & DSS, GFS & $\begin{array}{l}\text { VAS-head/neck, Neck Disability Index, Head- } \\
\text { ache Disability Index, EuroQol-5D, SF-12, } \\
\text { Zung Self-Rating Depression Scale }\end{array}$ & PRI \\
\hline Heiss et al., 2010 & 16 & Child + adult & SSR & NA & $\mathrm{Cl}$ \\
\hline Hekman et al., 2012 & 167 & Child + adult & DSS & $\operatorname{ccos}$ & $\mathrm{Cl}$ \\
\hline Hoffman \& Souweidane, 2008 & 40 & Child + adult & Gestalt & NA & $\mathrm{Cl}$ \\
\hline Hyun et al., 2013 & 30 & Child + adult & DSS & JOA score & $\mathrm{Cl}$ \\
\hline Kalb et al., 2012 & 104 & Child + adult & Gestalt + SSR & NA & $\mathrm{Cl}$ \\
\hline Kim et al., 2004 & 11 & Child & Gestalt & NA & $\mathrm{Cl}$ \\
\hline Klekamp, $2012^{36}$ & 107 & Unclear & DSS & Klekamp \& Samii score & $\mathrm{Cl}$ \\
\hline Klekamp, $2012^{37}$ & 359 & Unclear & Gestalt + DSS & Klekamp \& Samii score & $\mathrm{Cl}$ \\
\hline Koç et al., 2007 & 18 & Adult & DSS & Asgari score & $\mathrm{Cl}$ \\
\hline Kumar et al., 2008 & 87 & Child + adult & DSS & Klekamp \& Samii score & $\mathrm{Cl}$ \\
\hline Kunert et al., 2009 & 38 & Child + adult & Gestalt, GFS & Rankin Scale, Karnofsky Performance Scale & $\mathrm{Cl}$ \\
\hline Lam et al., 2013 & 22 & Adult & SSR & NA & PRI \\
\hline Lee et al., 2012 & 25 & Adult & Gestalt, SSR & NA & $\mathrm{Cl}$ \\
\hline Levo et al., 2010 & 46 & Child + adult & Gestalt & NA & $\mathrm{Cl}$ \\
\hline Limonadi \& Selden, 2004 & 24 & Child + adult & DSS & Limonadi score & $\mathrm{Cl}$ \\
\hline Litvack et al., 2013 & 110 & Child & SSR & NA & $\mathrm{Cl}$ \\
\hline Massimi et al., 2008 & 30 & Child & Gestalt + SSR & NA & $\mathrm{Cl}$ \\
\hline Massimi et al., 2011 & 15 & Child + adult & Gestalt & NA & $\mathrm{Cl}$ \\
\hline McGirt et al., 2006 & 130 & Child + adult & Gestalt & NA & $\mathrm{Cl}$ \\
\hline McGirt et al., $2008^{51}$ & 44 & Child & Gestalt & NA & $\mathrm{Cl}$ \\
\hline McGirt et al., $2008^{52}$ & 256 & Child & Gestalt & NA & $\mathrm{Cl}$ \\
\hline McGirt et al., $2008^{53}$ & 256 & Child & Gestalt & NA & $\mathrm{Cl}$ \\
\hline Mottolese et al., 2011 & 82 & Child & Gestalt & NA & $\mathrm{Cl}$ \\
\hline Mueller \& Oro', 2005 & 112 & Child + adult & GFS & Sickness Impact Profile & PRI \\
\hline
\end{tabular}


APPENDIX: Complete list of, and basic information about, each article meeting inclusion criteria (continued)

\begin{tabular}{|c|c|c|c|c|c|}
\hline Authors \& Year & $\begin{array}{l}\text { Sample } \\
\text { Size }\end{array}$ & $\begin{array}{l}\text { Participant Age } \\
\text { Group }\end{array}$ & $\begin{array}{l}\text { Outcome } \\
\text { System }\end{array}$ & Standardized Score & $\begin{array}{c}\text { Source of } \\
\text { Outcome Data }\end{array}$ \\
\hline Navarro et al., 2004 & 96 & Child & Gestalt & NA & $\mathrm{Cl}$ \\
\hline Noudel et al., 2011 & 11 & Child + adult & GFS & Noudel's adapted functional grading system & $\mathrm{Cl}$ \\
\hline Ono et al., 2007 & 27 & Adult & DSS & JOA score & $\mathrm{Cl}$ \\
\hline Ono et al., 2010 & 20 & Adult & DSS & JOA score + VAS-pain & $\mathrm{Cl}$ \\
\hline Panigrahi et al., 2004 & 21 & Child + adult & Gestalt & NA & $\mathrm{Cl}$ \\
\hline Perrini et al., 2007 & 24 & Adult & SSR & NA & $\mathrm{Cl}$ \\
\hline Prat \& Galeano, 2009 & 13 & Child + adult & Gestalt & NA & $\mathrm{Cl}$ \\
\hline Pritz, 2003 & 14 & Adult & Gestalt + SSR & NA & $\mathrm{Cl}$ \\
\hline Ramnarayan et al., 2008 & 51 & Child + adult & Gestalt + SSR & NA & $\mathrm{Cl}$ \\
\hline Romero \& Pereira, 2010 & 16 & Adult & Gestalt & NA & $\mathrm{Cl}$ \\
\hline Sakushima et al., 2013 & 232 & Child + adult & SSR & NA & $\mathrm{Cl}$ \\
\hline Shamji et al., 2010 & 24 & Child & Gestalt & NA & $\mathrm{Cl}$ \\
\hline Sivaramakrishnan et al., 2004 & 12 & Adult & Gestalt & NA & $\mathrm{Cl}$ \\
\hline Spena et al., 2010 & 36 & Adult & Gestalt & NA & $\mathrm{Cl}$ \\
\hline Takayasu et al., 2004 & 16 & Child + adult & Gestalt & NA & $\mathrm{Cl}$ \\
\hline Tisell et al., 2009 & 23 & Child + adult & GFS + SSR & VAS-quality of life & PRI \\
\hline Tubbs et al., 2004 & 22 & Child + adult & Gestalt & NA & $\mathrm{Cl}$ \\
\hline Tubbs et al., 2003 & 130 & Child + adult & Gestalt & NA & $\mathrm{Cl}$ \\
\hline Tubbs et al., 2011 & 500 & Child & Gestalt & NA & $\mathrm{Cl}$ \\
\hline Valentini et al., 2011 & 99 & Child & Gestalt & NA & $\mathrm{Cl}$ \\
\hline Ventureyra et al., 2003 & 24 & Unclear & Gestalt & NA & $\mathrm{Cl}$ \\
\hline Wetjen et al., 2008 & 29 & Child + adult & SSR & NA & $\mathrm{Cl}$ \\
\hline Williams et al., 2013 & 34 & Unclear & GFS & SF-36 & PRI \\
\hline Yeh et al., 2006 & 130 & Child & Gestalt & NA & $\mathrm{Cl}$ \\
\hline Yilmaz et al., 2011 & 82 & Adult & DSS & JOA score & $\mathrm{Cl}$ \\
\hline Zamel et al., 2009 & 80 & Child + adult & Gestalt & NA & $\mathrm{Cl}$ \\
\hline Zhang et al., 2011 & 132 & Child + adult & Gestalt & NA & $\mathrm{Cl}$ \\
\hline Zhang et al., 2008 & 316 & Child + adult & Gestalt & NA & $\mathrm{Cl}$ \\
\hline
\end{tabular}

$\mathrm{Cl}=$ clinician impression; DSS = disease-specific scale; GFS = general function scale; NA = not applicable; PRI = patient-response instrument; SF-12 = Short Form-12 Health Survey; SF-36 = Short Form-36 Health Survey; SSR = sign/symptom-specific reporting. 